\begin{tabular}{|l|l|l||}
\hline \multicolumn{2}{|c|}{ PublisherInfo } \\
\hline \hline PublisherName & $:$ & BioMed Central \\
\hline \hline PublisherLocation & $:$ & London \\
\hline \hline PublisherImprintName & $:$ & BioMed Central \\
\hline \hline
\end{tabular}

\title{
Septic shock without infection
}

\begin{tabular}{|l|l|l||}
\hline \multicolumn{2}{|c|}{ ArticleInfo } \\
\hline \hline ArticleID & $:$ & 4179 \\
\hline \hline ArticleDOI & $:$ & $10.1186 /$ ccf-1999-2441 \\
\hline \hline ArticleCitationID & $:$ & 2441 \\
\hline \hline ArticleSequenceNumber & $:$ & 38 \\
\hline \hline ArticleCategory & $:$ & Paper Report \\
\hline \hline ArticleFirstPage & $:$ & 1 \\
\hline \hline ArticleLastPage & $:$ & 3 \\
\hline \hline & & RegistrationDate : 1999-12-17 \\
ArticleHistory & $:$ & OnlineDate $\quad$ 1999-12-17 \\
\hline \hline ArticleCopyright & $:$ & Current Science Ltd1999 \\
\hline \hline ArticleGrants & $:$ & \\
\hline \hline ArticleContext & $:$ & 1305422 \\
\hline \hline
\end{tabular}




\section{Keywords}

Bacteraemia, infection, morbidity, mortality, organ failure, outcome, severe sepsis

\section{Comments}

This is an interesting retrospective analysis which highlights the continuing poor outcome in septic shock and identifies a subgroup of patients, without clinical or microbiological evidence of infection, who do significantly worse. These patients will always be a difficult group to treat but this study reinforces the importance of continued clinical and radiological searches for occult infection that is amenable to surgical drainage, and vigorous and repeated microbiological testing and sampling.

\section{Introduction}

Treatment of septic shock relies on supportive cardiovascular measures, identification of infection, and appropriate surgery or antimicrobial therapy to remove the organism. Unfortunately, an infecting organism isn't identified in up to $50 \%$ of patients who clearly have septic shock.

\section{Aims}

To determine whether outcome in septic shock differs between those patients with and without clinically or microbiologically identified infection.

\section{Methods}

Over a 3 year period (1993-1996) the data on patients treated for septic shock were retrospectively analysed. Septic shock was defined, and was not reliant on the identification of an infecting organism. Treatment of all patients followed the authors' standard intensive care unit (ICU) protocol. Conditions 
with known systemic inflammatory response syndrome (SIRS) responses, such as pancreatitis and trauma, were excluded. All possible specimens were taken for the identification of infecting organisms.

\section{Results}

In total, 227 patients received treatment for septic shock, of whom 30 patients (13\%) had no clinical or microbiological evidence of infection. Mortality was significantly higher in those patients with septic shock but no evidence of infection: $86 \%$ Vs $66 \% p<0.05$.

\section{Discussion}

The North American consensus conference defined septic shock as SIRS with confirmed infection, hypotension and evidence of hypoperfusion. Unfortunately a number of patients don't fulfill all these criteria but clearly should be included in this category of patient. There are a number of reasons why an organism may not have been isolated, including antibiotic use prior to ICU admission, incomplete microbiological testing for unusual organisms, and incomplete microbiological sampling. The likely explanation for the increased mortality seen in those patients without evidence of infection is that treatment was ineffective because incorrect antimicrobials were used or pus wasn't surgically drained.

\section{References}

1. Reyes WJ, Brimioulle S, Vincent J-L: Septic shock without documented infection: an uncommon entity with a high mortality. Intensive Care Med. 1999, 25: 1267-1270.

This PDF file was created after publication. 